\title{
Career Counseling Techniques Based on Career Chaos Theory
}

\author{
Chunlin Li \\ School of Political Science and Public Management \\ University of Electronic Science and Technology \\ Chengdu, China 610054
}

\author{
Qisheng He \\ Chinese People's Armed Police Force Academy in Chengdu \\ Chengdu, China 610000
}

\begin{abstract}
Several career counseling techniques that are based on career chaos theory was introduced, such as the signature exercise, table tennis fables, magic events retrospect and Professor Jin's C-U-C career counseling model. Career counselors can apply these techniques to help clients understand the nonlinear characteristics of career development and improve career cognition complexity. The client need to practice these techniques in order to break through the stereotyped thinking on career development and learn to make career decision both by left and right brain thinking. Through the process of searching, brewing, insight, compromise and practice, the good career adaptation can be achieved.
\end{abstract}

Keywords-career development; chaos theory; counseling techniques

\section{INTRODUCTION}

Career development is a 'process of evolution, involving the development of the task is not just "find a job", but "what kind of life", which contains the parties to the role of professional roles and various fantasy, Exploration, transformation and adaptation, is a complex interaction of multiple factors. The traditional career counseling paradigm lacks the full understanding of the complexity of career development, and tends to simplify the career counseling into the process of "confidant, knowledge and match", emphasizing the perfect "human-job match" through rational cognitive decision-, the goal of counseling is reducing the uncertainty of the party's career decisions. However, career development is far from following a simple, straightforward, logical path that has a non-linear feature.

The theory of career chaos reveals the nonlinear and dynamic characteristics of career development, specifically, there are the following points [1]:

- Self-generation and self-drive. Career development has the initiative to adapt to the characteristics of each person to a certain extent, according to their own script to create their own career process.

- An open dynamic system. As an adaptive entity, the individual is always in the internal and external environment for the exchange of open, network of participation, the deeper the involvement, the stronger the plasticity.
- Initial sensitivity. The slight difference in the starting state can lead to great variations if the iterations continue; the seemingly insignificant events tend to have unpredictable effects on the career development of the parties.

- There is no ultimate steady state. Everyone is looking for the steady state in stage, but the steady state is temporary, the phase change occurs at any time, the role of self because of "time bit" transformation so it is necessary to maintain flexibility.

- The role of attractors everywhere. There are two types of attractors, one similar to the "fixed number", such as fixed-point attractors, single-shot attractors, ring attractors, which make the adaptive entity in its role to maintain a certain convergence steady state, Holland's career Personality type is the kind of this attractor; the other is the singular attractor, it is the "fixed number" of the reactionary, the mutation of the promoter, such as some unexpected events.

- Fractal features. Fractal is a kind of self - similar structure, career cycle in the development of large cycle of nested small cycle, the size of the cycle of cycle there is some sort of order, similarity.

The lack of sufficient understanding of the chaotic nature of career development can lead to the following problems: (1) Career development must step by step, can't tolerate the slightest change, and be deviations from expectations is considered as frightening and intolerable; Feel too much, lack of flexibility and flexibility. The determinants of career development in a limited range of intolerance, lack of adequate consideration of possible variables; or too much emphasis on one aspect of the influence, the interaction of multiple factors ignored; ignoring the factors of career development opportunities. (2) Paying too much attention to rational cognitive decision-making, ignore the excavation of unconscious information, and can't use the brain in the process of career adjustment. These problems will seriously weaken the party's ability to adapt to life, resulting in decision-making hesitation, anxiety and stagnation of the state. Then several career counseling techniques derived from career chaos theory are introduced. The technology of the original Pryor and Bright [2], and the impact of these factors change multiple attribute technology is designed to 
help visitors understand the career development, through the left and right brain breakthrough thinking, explore, experience repeated brewing fermentation and compromise the development of practice links, to achieve good career adaptability.

\section{TeChnOlogy One: Signature Practice}

- Objectives: (1) to clarify the real world is essentially self organization (self-organizing) and random principle under the action of the product; (2) complex system in the operation process not only follow some stable models also have a random change; (3) career development not only has the order of random;(4) simple practice also can not completely control; (5) reveal the differences of two kinds of ideas: one to see the world, and to determine the linear mechanical point of view, another to open and integrate with and adapt to the perspective of the world.

- Participants: This exercise applies to visitors who lack sufficient knowledge of the chaotic features of career development. Some visitors have been aware of career development is not completely follow the inherent mode, no ultimate purpose, but some people are not aware of this, they are unwilling to admit certain aspects of career development is insufficient and even completely out of control. Especially for engineering students, they look at the world from a rigorous mechanical positivist perspective, believing that everything follows the law of cause and effect, and that the consequences can be predicted as long as they grasp the antecedents.

- Material: Standardized blank paper, signature pen, stopwatch

- Program: The standardization of blank paper and pen to inform them once the main subjects, try a start signal, on the blank paper as much as possible to write his signature, for 30 seconds, until I stopped writing at the end of a signal. The subject may have checked the bottom of the blank sheet from top to bottom. If the exercise is not over, the main test should remind the participant of another column. During the exercise, the master will not give any explanation for the purpose of the exercise. If asked, you need to explain that the whole exercise takes less than a minute. Please be more patient and trusting. Focus your attention on signing exercises without worrying about it. For those who are really impatient, it takes more time to develop a good relationship of trust (rapport).

- After the exercise, it is guided observation. The test subjects were asked to find the differences between the signatures, such as font size, inclination, writing strength, speed, direction, spacing, stroke connections, and special wording. Most of the subjects can better identify the minor differences between the signatures. The main test can encourage them to speak out, and ask: "since there are so many differences between these signatures, can they represent your signature?"" Yes, most of them are positive answers.

- The following is the main test summary: All signatures of the same person have a clear pattern (it looks like the same, and can be identified as from one person), but also have different signatures between random variation, some minor differences as mentioned above.

\section{TeChnOlogy Two: TABle TenNis AllegoricAL}

In foreign countries, many myths, fairy tales and fables are the counseling techniques that counselors can choose to stimulate the creativity, self-awareness and career exploration of visitors, [3]. At present, some of the techniques available to career counselors are too long, too unfamiliar, and too difficult to be used by some visitors. Therefore, it is necessary to develop a tutoring technique that is more family oriented and more closely related to daily life. The use of table tennis fables is such a technique. It can be presented at the beginning of career counseling in the form of words, words or cartoons.

- Objectives: (1) revealed the increasing complexity of how to inevitably lead to predictable decline; (2) to clarify: Although people predict a situation, but can try to understand and explain, no need to deliberately pursue complete control; (3) reveal the evolution is influenced by multiple factors, nonlinear the characteristics of phase transformation; (4) (phase shift) concept; (5) stressed: in the decision-making process, human beings have the information and the control limitations; (6) stressed: in the condition of incomplete information, in the dynamic conditions of decision-making is difficult to avoid.

- Applicable Scope: The initial stage of table tennis in the fable of career guidance as a stress free family practice using, it can inspire visitors to a new perspective on personal situation, occupation activities and daily life, will be very helpful for subsequent career counseling. The parable is very useful for individuals who are obsessed with career decision-making. It objectively points out that most decisions that affect career development are conducted under incomplete information and limited control of the future. The parable also subverts the traditional notion that "all questions have answers" or "a choice can solve all problems".

- Program: In the case of individual counseling, the technology available in the counseling process batch as a family practice, but also can be used as separate guidance fragments, the premise is between mentors and visitors have established a good relationship of trust, otherwise some suspicious visitors asked the correlation of practice and career guidance, because occupation indeed, other topics work and career guidance to be involved on the surface of table tennis is independent of the fable. 
If the visitor lacks reading ability, the main test can tell or play the recording to let him understand the main plot of the story. Sometimes it is necessary to present the plot in a cartoon, and the visualization of the story will help to understand it. The main test does not require superb painting skills, only the whole story is divided into 6 to 10 fragments, in the form of a sketch on the square paper. As long as the counselor has a little bit of confidence in his painting skills, visitors will be patiently involved in the presentation of the story, making the allegorical story more effective.

\section{A. Conclusion}

From the people of table tennis in the fable of Enlightenment (1) it is problematic for any mechanical prediction of career development, and it is not the goal of career guidance; (2) the adequacy of the complexity of reality and variables makes accurate prediction and control to achieve; (3) for the complex situation the details of the development can only make the explanation afterwards rather than ex ante prediction; (4) the reality of complexity, easy to change, and sometimes change, therefore, career consultants and visitors should not be limited to the individual and occupation for matching analysis is simple, but should focus on change, lifelong learning. Appropriate changes consciously, and benefit from the change in.

\section{TeChNOlogy Three: MAgicAl EVEnt REVIEW}

- Objectives: (1) arouse the special experience of individual unusual and contrary to expectation of life and learning consciousness, this kind of magical events (such as a completely unintentional novel ty found) may give the individual career development to bring the unexpected effect; (2) to help the individual proved important insight of its life from where (3) and that makes his) suddenly become creative, transparent environment model is how to operate.

- Material: this exercise stems from an active design of Vallence and Deal [4]. Pryor and Bright introduced it into career counseling and made appropriate changes in the material (see Appendix A). A total of 10 slides were used, each showing a color related picture and a statement, such as: "when I met a good teacher, something magical happened."." Among them, "when I am."..... When the magic happened "is a common part of each slide in different parts of the ellipsis statement

- Procedure: the following instructions are made before the individual practices this exercise: unexpected, unplanned accidents often occur, and people are often surprised at such events. In this process, people usually get new knowledge about themselves, others, and the world as a whole. In this sense, career development is magical and unpredictable. The magical events slide (card) presents some typical scenes in which magical events may have occurred to you. By reviewing these experiences, people can rediscover their career development, learn how to create conditions, meet opportunities, and benefit from them.

- Slide show: Visitors are asked to choose from the 10 slides the number of special memories they can evoke. Limit the number of slides selected according to the adequacy of the subsequent discussion time. If the time is limited, the choice is limited to 5 sheets, and there is no limit to the amount of time. If you need to further reduce the number of selected scenes, let the subjects select the most typical, the most magical, and the most impressive scenes in the selected slides again.

- The retrospective phase of the magical event: the subjects are asked to recall the magical events associated with the slides and describe them in detail. The main question: (1) what do you think of the magic of this experience? (2) What do you think of yourself, others, the whole world and life? (3) What strategies do you take during this period? Which ones work? Which ones are invalid? (4) Do you want this event to happen again? Why? (5) What would you do if you were given another chance? How will things change?

From the selection of slides, to the recollection of relevant experiences, to the whole practice process of inspiration, can be repeated. You need to select a new set of slides for each repetition. After a series of repetitions, visitors record a set of magical events that have been associated with them. After that, they will spontaneously reflect on these experiences and reflect what firm values and behavior patterns. In this process, the fractal visitors will come to realize the career development "(fractal)" features, namely their behavior seems to follow a stable operation mode, the performance of similar features (self-similar). This characteristic is revealed by the theory of career chaos.

\section{TeCHNOLOG Four: THE C-U-C MOdEL}

Shuren Jin proposes a C-U-C [5] model, the basic assumption is: (1) the essence of career decision is to seek shelter and life, "home" is the target surface, is to maintain the balance of the maximum possible state of existence; "life" is deep, and lies close to fulfilling your destiny. (2) People have the wisdom to make career decisions, and the greatest wisdom needs to be left and right, so intentional reasoning is just as important as unintentional discovery. (3) Complete the career decision is a kind of a middle course. Its characteristic is in the rational thinking mode, adding to the subconscious intuition based care stage, with rich color China a middle course. C-U-C (ConsciousnessUnconsciousness-Compromise) model includes the "consciousness" and "subconscious", "moderation" three stages.

- The first stage: conscious awareness of your problems, career exploration, or rational analysis. Some of the party's career problems can be resolved at this stage. If a considerable amount of effort is 
made, it is difficult for the party to make a decision and move on to the next stage.

- The second stage: accumulation, brewing, listening to the call of the heart, waiting for the moment of enlightenment. Decisions on small things depend on the mind; decisions on big things depend on the mind. At this stage, the parties must be experienced in a predicament, leave no stone unturned, suspicious, puzzled, tired state. Thoughts are confused and reason is lax. The chaotic state of the parties, also let the consultants feel exhausted at. In a break from consciousness, provides the opportunity for dense willow trees and bright flowers. These opportunities include the planned happenstance, [6], and the application of simultaneous (synchronicity) concepts [7]. The following methods in this phase reference: (1) insight. Intentional, not judgmental, in the present. Put everything aside for the thought drain. Through meditation or meditation, listen to the slightest sound, sublimation from the heart, without any judgment, just feel; (2) career fantasy tour. Guided by the guiding language of "future typical day", it emerges in the scene of fantasy tour. The design of career fantasy is to leave consciousness in a relaxed and alert atmosphere, and to let the desires of reality be realized through the images of the mind. (3) Metaphor of dreams. "When you really desire something, the whole universe will unite to help you accomplish it."." True desires often derive metaphors from dreams. This is not the only approach at this stage. "I always try to make room for everything that comes to me from the bottom of my heart," Carl Jung said." As long as the heart desires, as long as the psychological space, whether it is divine, cable dream, tarot cards, external universe response, is likely a small universe and inner desire to be connected.

- The third stage: compromise, pragmatic practice. The expectation of the compromise stage is the transformation of experience. The reality of inner sublimation must be balanced with external reality. How should the precipitation of this experience be carried out? At this stage, the specific approach, C-U$\mathrm{C}$ model proposed to adopt: (1) expressive writing (expressive, writing). In the process of writing, the writer is not a pure writer, and the subject of mind becomes a description of the object. To the view of "the other" or position, to recognize and understand the conflict, seek wisdom out of the. There are many forms of expressive writing, including poetry, autobiography, fiction, prose, diaries, letters....... (2) Diary writing of psychological shift. Shuren Jin developed the writing style of psychological shift from Xingjian Gao's experience of "Lingshan", which is called "psychological displacement paradigm in diary-writing: PDPD". The method of PDPD is to let the client write a diary in the three positions of me, you and him. First, it is customary to use the first person "me" to write the day or recent event or mood. When you have finished, take a blank line and change the subject to the second person". Once you have written it, take a blank line and change the subject to "third person"". During the career counseling process, PDPD's writing theme is an exploration of reason and intuition. The expression of diary writing by means of this, let the operation move in my consciousness, you and his person, causing "non-self", "you" and "he", to help the parties from "just because in the mountains" limitations.

\section{CONCLUSION}

Career chaos theory reveals the complex nature of career development, and also changes the traditional career guidance model. The goal of career guidance in the context of chaos theory is to train the party's career adaptability and promote continuous learning and development. Once the Vichy (2009) put forward the concept of career meta competency, meaning searching, open and flexible, practical action, optimistic, tenacious perseverance is the five basic competency [8]. Career counselors can help visitors develop these qualities through the above consulting techniques. Signature exercises and table tennis fables can help visitors to gain insight into the chaotic nature of career development, making them less aware of career development, not rigid and expanding cognitive complexity. The magical event review can help visitors learn the association and analysis of career experiences, thus fully accepting and rationally utilizing the chance coincidence in the chaotic background. Shuren Jin's C-U-C can break through the traditional service model of rational decision model limitations, to help visitors better listen to your inner voice, persist in hardship, meaning in the brewing of enlightenment and Enlightenment of wisdom.

\section{REFERENCES}

[1] Weixi Zeng. The chaotic characteristics of career development and the paradigm integration of career counseling $[\mathrm{J}]$. Journal of Southwest Agricultural University (Social Science Edition),2011, 9(12):181-185

[2] Pryor, R. G. L., Bright, J. E. H. Chaos in practice: Techniques for career counselors. Journal of employment counseling [J], 2006, 43(1), 9-17.

[3] Amundson, N. Walking the yellow brick road. Journal of Employment Counseling [J], 2006, 43:31-38.

[4] Vallenee, K., Deal, R. Sometimes magic: Celebrating the magic of everyday learning [M]. 2001.

[5] http://group.datihu.com/document/20110608_hangzhou/download/sp eech/speech_jinshuren_buchong.pdf (Professor Shuren Jin's Speech at the Forum on Chinese Culture and Career Education)

[6] Krumblotz, J. D. Serendipity is not serendipitous. Journal of Counseling Psychology [J], 1998, 45(4), 390-392.

[7] Shuren Jin. Career counseling and coaching [M].Beijing: Higher Education Press, 2007.

[8] Weixi Zeng. A Study on the Types and Crux of Uncertainty of College Students' Career [D].Chongqing: Doctoral Dissertation of Southwest University, 2009. 